\title{
Bioassay of Environmental Exposure of Children to Polycyclic Aromatic Hydrocarbons Using 1-Hydroxypyrene
}

\author{
Leila Ibrahimi Ghavam Abadi ${ }^{1}$; Behzad Fouladi Dehaghi ${ }^{2, *}$; Mathaerh Boazar $^{2}$ \\ ${ }^{1}$ Department of Environmental Management, College of Agriculture, Ahvaz Branch, Islamic Azad University, Ahvaz, IR Iran \\ ${ }^{2}$ Department of Occupational Health, School of Public Health, Ahvaz Jundishapur University of Medical Sciences, Ahvaz, IR Iran \\ *Corresponding author: Behzad Fouladi Dehaghi, Department of Occupational Health, School of Public Health, Ahvaz Jundishapur University of Medical Sciences, Ahvaz, IR Iran. \\ Tel/Fax: + 98-6133738282, E-mail: bdehaghi@gmail.com
}

Received: February 22, 2015; Revised: March 17, 2015; Accepted: April 7, 2015

Background: Polycyclic aromatic hydrocarbons (PAHs) are a group of main air pollutants which are produced by motor vehicles and are known as carcinogens.

Objectives: This study was conducted to investigate the environmental exposure of children to PAHs using urinary 1-hydroxypyrene (1OHP) measurement.

Patients and Methods: A total of 260 participants enrolled in the study, aged between 6-12 years. Environmental exposure due to urban traffic and tobacco smoke was investigated. Morning and evening urine samples were collected and 1-OHP concentrations were measured. High-performance liquid chromatography (HPLC) with fluorescence detector, used for sample analysis, and 1-OHP concentrations in urine samples, corrected by urinary creatinine, were determined for PAHs exposure assessment. Information on environmental tobacco smoke (ETS) exposure at home and air pollution of the residential area as a measure of heavy traffic and living close to busy highways were collected using a self-administrated questionnaire.

Results: In general, the results showed that males had higher 1-OHP levels than females $(\mathrm{P}<0.05)$. The total morning levels were $0.47 \pm 0.12$ $\mu \mathrm{mol} / \mathrm{mol}$ crea vs. $0.63 \pm 0.15 \mu \mathrm{mol} / \mathrm{mol}$ crea for evening. In the presence of ETS, higher 1-OHP concentrations were observed in morning samples. In addition, living in a polluted area is strongly associated with higher levels of 1-OHP.

Conclusions: Taking into account that Iran is a developing country with a young population and numerous PAHs sources, environmental exposure to PAHs at these levels can be dangerous for children's health. Furthermore, PAHs can be declared as national concerning environmental pollutants.

Keywords: Polycyclic Aromatic Hydrocarbons; Children;1-Hydroxypyrene; Environmental Exposure; Biomonitoring

\section{Background}

Fast industrialization of developing countries has resulted in negative impacts on the environment and health of the population. World Health Organization (WHO) announced that air pollution in the Asia and Pacific region is an important problem (1). Rate of population growth in Asia is high; therefore, the issue of children's environmental health is certainly a significant one in this part of the world (2). One of the most important public health concerns is paying attention to the relation between environmental contaminant exposure and illnesses in children, even with a delay (3-5). In large cities like Tehran, Iran, there are several air pollutants which affect the health of people, especially in areas with high traffic burden. Carcinogenic agents in air pollution are a significant menace and need serious attention (6). Polycyclic aromatic hydrocarbons (PAHs) are a group of main air pollutants produced and emitted by motor vehicles to air and are known as carcinogenic agents (7-12). PAHs are a group of three- and four-ring chemical compounds, produced as a result of incomplete combustion of fuel
(13). There are industrial and nonindustrial sources of environmental pollutant, with the most common sources being cigarette smoke, coal fired utilities, steel plants, motor vehicle exhaust, wood burning ovens and fire places, and charcoal-grilled and smoked food $(14,15)$. Rate of exposure to environmental contaminants such as air pollution, soil, and dust is higher in children than adults. Since children have different and specific behavior patterns including hand to mouth activity, they have more inhalation rate and more time spent close to and on the ground compared with adults $(9,16)$. PAHs are a mixture of compounds and pyrene is almost always found in such mixtures. 1-hydroxypyrene (1-OHP) as pyrene metabolite is considered as an appropriate alternative marker of total PAH exposure (17). Urinary 1-OHP represents the last 24 hours of cumulative PAHs exposure (18). Several researchers have been used and validated 1-OHP in exposure assessment of industrial workers (19-22). Generally, 1-OHP levels are lower by one or two orders of magnitude, depending on smoking habits and background exposures.

Copyright (c) 2015, Ahvaz Jundishapur University of Medical Sciences. This is an open-access article distributed under the terms of the Creative Commons Attribution-Non Commercial 4.0 International License (http://creativecommons.org/licenses/by-nc/4.0/) which permits copy and redistribute the material just in noncommercial usages, provided the original work is properly cited. 
In reviewing the data on children's environmental exposure assessment (the case of PAHs), most of the studies found that the main routes of exposure of children are environmental tobacco smoke and heavy traffic.

\section{Objectives}

In the present study, the effect of exposure to urban traffic-induced air pollution and environmental tobacco smoke at home was assessed, with regard to PAHs exposure in Iranian children through urinary 1-OHP measurement.

\section{Patients and Methods}

\subsection{Study Population}

A total of 260 children, aged 6 - 12 years, living in Tehran, enrolled in this study. The children were randomly selected and both genders were involved. Half of them lived in areas with high traffic burden (close to main roads with a mean daily frequency of about 20000 - 40000 vehicles) and many industrial sites and thus a high level of air pollution and the other half lived in a cleaner part of the city with low traffic density (below 5000 vehicles/day). The parents were given full information about the aim and objectives of the study. After receiving their written informed consents, they were asked to fill out a structured questionnaire containing some questions on children's health, possible sources of children's exposure to air pollution and PAHs, which also included information on parents' smoking habits (at least 5 - 10 cigarettes a day at home) and perception of residential traffic density. The data on age, gender, weight, and second-hand smoke exposure were derived from the questionnaires.

\subsection{Urinary 1-Hydroxypyrene Measurements}

Children's morning urine samples $(30 \mathrm{~mL})$ were collected by parents and were kept at room temperature till delivered to the person responsible for collection and delivery of the samples to the laboratory. Again, in the evening, another urine sample was taken from each child and was sent to the laboratory. The questionnaires were also collected. The samples were kept at $-20^{\circ} \mathrm{C}$ until analysis. For the analysis of 1-OHP, the method developed by Jongeneelen $(23,24)$ was used. In short, urine samples (10 cc) were buffered with sodium acetate buffer $(\mathrm{pH}=5)$ and hydrolyzed enzymatically using $\beta$-glucuronidase/arylsulfatase Helix Pomatia (Sigma-Aldrich, Germany) for 16 hours at $37^{\circ} \mathrm{C}$ in a shaking water bath. After the hydrolysis, the sample was loaded on a C18 cartridge primed with 10 $\mathrm{mL}$ methanol followed by $5 \mathrm{~mL}$ ultra-pure water, with the aim of a slight vacuum at the flow rate of approximately $10 \mathrm{~mL} /$ minute. After loading the samples, the cartridge was washed with $10 \mathrm{~mL}$ water and the analyte was eluted with $9 \mathrm{~mL}$ of high-performance liquid chromatography (HPLC) grade methanol. A vac-elute vacuum elution system was used for retention and elution processes of silica cartridges. $\mathrm{pH}$ measurement was performed with a digital pH meter (Hanna, Singapore). Quantitative liquid transfers were performed with pipette [Socorex, Germany]. The HPLC apparatus consisted of a k-1001 single piston pump (Knauer, Germany); the analytical column was an RP-C18 $\mathrm{e}^{5} \times 4.6 \mathrm{~mm}$ (Merck-KuaA, Germany); the detector was florescence RF-10AXL (Knauer, Germany) attached to the HPLC. 1-OHP concentrations were corrected using creatinine concentration and expressed in $\mu \mathrm{mol} /$ mol creatinine.

\subsection{Statistical Analysis}

All the statistical analyses were performed using SPSS software package version 19.0 (SPSS Inc., IBM). To have a good vision of the data collected, descriptive statistics were calculated and mean, standard deviation (SD), min and max for 1-OHP concentrations, both in morning and evening samples, age, and gender of the participants were determined. The data was first tested to be normal using Kolmogorov-Smirnov test. The data showed a good normality, so the tests for parametric distribution were performed. The differences in means of different groups of children were assessed using student's t-test. Multiple regression analysis was also performed to examine the relationships between the variables. Statistical significance of the data was assumed if the $\mathrm{P} \leq 0.05$.

\section{Results}

Morning and evening urine samples were collected from 260 healthy children. The group size of males was equal to females, each consisted of 130 children aged 6 12 years; $53.12 \%$ of children lived in houses with a smoker parent. 1-OHP concentrations for both genders in morning and evening are presented in Table 1 . To adjust individual differences in spot urine samples, the concentrations of 1-OHP are adjusted for creatinine, so the reported concentrations are $\mu \mathrm{mol} 1-\mathrm{OHP} / \mathrm{mol}$ creatinine. As Table 1 shows, the mean 1-OHP concentrations for males were significantly higher than females $(P<0.01)$ both for morning and evening. Therefore, there was a significant difference between genders in the amount of urinary excreted 1-OHP.

\begin{tabular}{lccc}
\hline \multicolumn{4}{l}{ Table 1. 1-Hydroxypyrene Concentrations in Children } \\
& Female $^{\mathrm{b}}$ & Male $^{\mathrm{b}}$ & PValue $^{\mathrm{b}}$ \\
\hline Morning & $0.39 \pm 0.06$ & $0.51 \pm 0.11$ & 0.001 \\
Evening & $0.51 \pm 0.10$ & $0.67 \pm 0.14$ & 0.001 \\
\hline
\end{tabular}

\footnotetext{
a Data are presented in $\mu \mathrm{mol} / \mathrm{mol}$ crea.

b Data are presented as mean \pm SD for 130 participants.
}

In addition, males had higher concentrations, which is significantly different from females. To examine the effect of exposure to second-hand cigarette smoke, some tests were performed. For all the participants, morning 
concentrations of 1-OHP in relation to second-hand tobacco smoke were significant $(\mathrm{P}=0.02)$, which means that exposure to tobacco smoke at home leads to higher 1-OHP concentrations in the morning. However, the result of the same test for evening concentrations was not significant. When the test was performed just for females, no significant data was obtained for morning or evening. The test for males with regard to exposure to tobacco smoke was also performed and for morning concentrations of 1-OHP a significant result was obtained $(\mathrm{P}=0.04)$; but for evening, the results were not significant. Another stage of statistical analysis was performed to evaluate the effect of air pollution and heavy traffic (urban environmental exposure) on concentration of 1-OHP. A group of children lived in an area with a polluted air $(\mathrm{N}=162)$ and the other group lived in a cleaner part of the city $(\mathrm{N}=98)$. Statistical analysis using student's t-test showed that in females, there was a significant difference in the amount of 1-OHP in urine of children with regard to the level of air pollution in the area they lived, and of course, 1-OHP was higher in children from the polluted area; for instance, $0.55 \pm 0.07 \mu \mathrm{mol} 1-\mathrm{OHP} / \mathrm{mol}$ creatinine in the evening for females from the polluted area vs. $0.45 \pm 0.12 \mu \mathrm{mol}$ $1-\mathrm{OHP} / \mathrm{mol}$ creatinine in the evening for females from the cleaner area $(\mathrm{P}<0.001)$. Table 2 presents the results of such tests. Both morning and evening concentrations of 1-OHP in both genders had significant differences due to the amount of air pollution in the area of residence. According to the t-test there was a strongly significant difference between the two groups considering the total of the subjects, $(\mathrm{P}<0.001)$. Considering ETS and the area of residence, the results showed that in both genders, there was a significant difference between the group living in a polluted area and the group living in a cleaner part of the city. However, when the test was performed for children without ETS, the differences were significant for both morning and evening concentrations of 1-OHP. Table 3 presents a brief summary of the results. Finally, the test showed that for females, the morning concentration of 1-OHP was significantly different from the evening concentration, with a higher level in the evening $(\mathrm{P}<0.001)$. For males, again, the morning and evening levels of 1-OHP were significantly different $(\mathrm{P}<0.001)$ and the evening level was also higher.

\begin{tabular}{|c|c|c|c|c|}
\hline & No. & Morning ${ }^{b}$ & Evening $^{b}$ & P Value \\
\hline \multicolumn{5}{|c|}{ Living in a Polluted Area } \\
\hline Male & 81 & $0.57 \pm 0.05$ & $0.47 \pm 0.04$ & 0.05 \\
\hline Female & 81 & $0.43 \pm 0.02$ & $0.55 \pm 0.07$ & 0.001 \\
\hline \multicolumn{5}{|c|}{ Living in a Non-Polluted Area } \\
\hline Male & 49 & $0.42 \pm 0.12$ & $0.54 \pm 0.15$ & 0.001 \\
\hline Female & 49 & $0.31 \pm 0.04$ & $0.45 \pm 0.12$ & 0.001 \\
\hline Total & 260 & $0.47 \pm 0.12$ & $0.63 \pm 0.15$ & 0.001 \\
\hline
\end{tabular}

a Data are presented in $\mu \mathrm{mol} / \mathrm{mol}$ crea.

$\mathrm{b}$ Data are presented as mean $\pm \mathrm{SD}$.

\begin{tabular}{|c|c|c|c|c|}
\hline Living Form & No. $(\%)$ & Morning & Evening & P Value \\
\hline \multicolumn{5}{|c|}{ Living in a Polluted Area } \\
\hline \multicolumn{5}{|c|}{ Male } \\
\hline With ETS & $49(30)$ & $0.60 \pm 0.04$ & $0.74 \pm 0.04$ & 0.04 \\
\hline Without ETS & $33(20)$ & $0.53 \pm 0.04$ & $0.75 \pm 0.05$ & 0.05 \\
\hline \multicolumn{5}{|l|}{ Female } \\
\hline With ETS & $41(25.2)$ & $0.43 \pm 0.02$ & $0.56 \pm 0.07$ & 0.001 \\
\hline Without ETS & $40(24.8)$ & $0.42 \pm 0.03$ & $0.55 \pm 0.07$ & 0.001 \\
\hline Total & $162(100)$ & $0.50 \pm 0.08$ & $0.65 \pm 0.11$ & 0.02 \\
\hline \multicolumn{5}{|c|}{ Living in a Non-Polluted Area } \\
\hline \multicolumn{5}{|c|}{ Male } \\
\hline With ETS & $32(33)$ & $0.49 \pm 0.01$ & $0.63 \pm 0.05$ & 0.001 \\
\hline Without ETS & $16(16.4)$ & $0.26 \pm 0.07$ & $0.35 \pm 0.01$ & 0.001 \\
\hline \multicolumn{5}{|l|}{ Female } \\
\hline With ETS & $16(16.4)$ & $0.32 \pm 0.00$ & $0.53 \pm 0.22$ & 0.001 \\
\hline Without ETS & $33(34.2)$ & $0.31 \pm 0.05$ & $0.41 \pm 0.06$ & 0.001 \\
\hline Total & $98(100)$ & $0.37 \pm 0.10$ & $0.49 \pm 0.14$ & 0.05 \\
\hline
\end{tabular}

$\mathrm{a}$ Data are presented in $\mu \mathrm{mol} / \mathrm{mol}$ crea.

b Abbreviation: ETS, environmental tobacco smoke. 


\section{Discussion}

This study was one of the first attempts to investigate children's exposure to PAHs in Iran and detected an association between urinary excretion of 1-OHP and dense traffic-related air pollution and with environmental tobacco smoke at home (smoking at least 5 - 10 cigarettes a day at home), suggesting that emissions from motor vehicles in dense traffic patterns can play an important role in children's exposure to PAHs in Iran. Furthermore, exposure to ETS has proved its role in increasing the 1-OHP levels in urine of exposed participants. The highest levels of 1-OHP was found in the urine of boys living in polluted areas of Tehran with a smoking parent who smoked at least 5 - 10 cigarettes a day at home (Table 3). The difference between children living in different parts of Tehran was of a significant nature $(\mathrm{P}<0.05)$. Urban air pollution, dense traffic burden and presence of a smoker at home are of the main reasons of children's environmental exposure to PAHs. Similarly, other researchers also reported that the highest concentration of 1-OHP was for children living in polluted areas. Therefore, the urban traffic was stated to be of the most importance (2527). Northridge et al. in investigating urban sources and traffic effect on 1-OHP concentration in children of 12 - 14 years old living in New York urban areas with dense traffic and exposure to diesel exhaust, stated that these are the most important sources of environmental exposure to PAHs (28). Several studies have shown that increased PAHs exposure from urban sources (e.g. diesel exhaust) and local industries contribute significantly to 1-OHP levels in people of these areas, especially in children (29). There are a few studies investigating the gender effect on 1-OHP concentrations. One of these studies performed by Jongeneelen et al. showed that gender is of an important role, because there are some gender-related behaviors which affect the final 1-OHP concentrations (30). Our study also proved the importance of being a male in case of higher PAHs exposure and higher 1-OHP levels. Other studies did not state any differences in concentrations for both genders $(22,24,26)$. Mostly males were assessed and the assumption was based on no difference between the genders in 1-OHP concentrations. Gender affects PAHs exposure and thus 1-OHP concentrations. 1-OHP is generally higher in males, but a study performed on Ukrainian children found higher concentration of 1-OHP in females (28). However, when the data was adjusted to creatinine, the significance was no more valid. Several studies have shown that tobacco smoke contains PAHs and relates to more 1-OHP excretions. 1-OHP levels in smokers are higher than non-smokers (31). Similar to our findings, some studies on children have tried to investigate the role of ETS in 1-OHP concentrations (26, 29, 32-35). ETS showed a significant role just when comparing the mean of 1-OHP between exposed and non-exposed groups. Not all the researchers have found such a relationship, maybe because of greater roles of other industrial and environmental sources (35-37). In the present study, when comparing males and females with regards to ETS exposure, no significant difference was observed in lack of exposure to ETS. It might be due to several different domestic and environmental sources and environmental backgrounds. In another part of the study, multiple regression analysis showed that children, especially boys, living in urban areas with high levels of air pollution due to dense traffic burden and in the presence of a smoker at home, had higher levels of urinary 1-OHP. Environmental exposure to PAHs has proved adverse effects and the concentrations reported here are capable of introducing danger for children's health. Further research is needed to identify and lessen the main sources of children's exposure to PAHs. Furthermore, there is a need to investigate PAHs exposure from different sources and to use even more specific biomarkers of exposure, to be able to promote national health and welfare.

\section{Acknowledgements}

The authors appreciate the participating parents and children for their interest and enthusiasm to participate in the study.

\section{Authors' Contributions}

Leila Ibrahimi Ghavam Abadi; study concept, design, definition of intellectual content, literature search, experimental studies, data acquisition, manuscript preparation and editing and review. Behzad Fouladi Dehaghi; study design, literature search, experimental studies, data acquisition, data analysis and statistical analysis. Mathaerh Boazar; statistical analysis.

\section{References}

1. WHO.. The world health report 2002: Reducing risks, promoting healthy life. World Health Organization editor. Geneva: World Health Organization; 2002.

2. UN.. World Population Prospects. The 2004 revision database. United Nations editor. New York: United Nations; 2003.

3. Al-Daghri NM, Alokail MS, Abd-Alrahman SH, Draz HM, Yakout SM, Clerici M. Polycyclic aromatic hydrocarbon exposure and pediatric asthma in children: a case-control study. Environ Health. 2013;12:1.

4. Suk WA, Murray K, Avakian MD. Environmental hazards to children's health in the modern world. Mutat Res. 2003; 544(23):235-42.

5. Suk WA, Ruchirawat KM, Balakrishnan K, Berger M, Carpenter D, Damstra T, et al. Environmental threats to children's health in Southeast Asia and the Western Pacific. Environ Health Perspect. 2003;111(10):1340-7.

6. Ruchirawat M, Navasumrit P, Settachan D, Autrup H. Environmental impacts on children's health in Southeast Asia: genotoxic compounds in urban air. Ann N Y Acad Sci. 2006;1076:678-90.

7. IARC.. IARC monograph on evolution of the carcinogenic risk of chemicals to humans: Poly nuclear aromatic hydrocarbons part 4.Lyon: International Agency for Research on Cancer; 1984

8. IARC.. IARC monograph evolution of the carcinogenic risk of chemicals to humans: Overall evaluations of carcinogenicity: on updating of IARC monograph.Lyon: International Agency for Research on Cancer; 1987.

9. Ruchirawat M, Navasumrit P, Settachan D, Tuntaviroon J, Buth- 
bumrung N, Sharma S. Measurement of genotoxic air pollutant exposures in street vendors and school children in and near Bangkok. Toxicol Appl Pharmacol. 2005;206(2):207-14.

10. Leroyer A, Jeandel F, Maitre A, Howsam M, Deplanque D, Mazzuca $\mathrm{M}$, et al. 1-Hydroxypyrene and 3-hydroxybenzo[a]pyrene as biomarkers of exposure to PAH in various environmental exposure situations. Sci Total Environ. 2010;408(5):1166-73.

11. Kang Y, Shao D, Li N, Yang G, Zhang Q, Zeng L, et al. Cancer risk assessment of human exposure to polycyclic aromatic hydrocarbons (PAHs) via indoor and outdoor dust based on probit model. Environ Sci Pollut Res Int. 2015;22(5):3451-6.

12. Boada LD, Henriquez-Hernandez LA, Navarro P, Zumbado M, Almeida-Gonzalez M, Camacho M, et al. Exposure to polycyclic aromatic hydrocarbons (PAHs) and bladder cancer: evaluation from a gene-environment perspective in a hospital-based casecontrol study in the Canary Islands (Spain). Int J Occup Environ Health. 2015;21(1):23-30.

13. IARC.. Polycyclic aromatic hydrocarbons in air and their effect on human health.Lyon: International Agency for Research on Cancer; 2003.

14. Hunter S, Myers S, Radmacher P, Eno C. Detection of polycyclic aromatic hydrocarbons (PAHs) in human breast milk. Polycycl Aromat Comp. 2010;30(3):153-64.

15. Bortey-Sam N, Ikenaka Y, Akoto O, Nakayama SM, Yohannes YB, Baidoo E, et al. Levels, potential sources and human health risk of polycyclic aromatic hydrocarbons (PAHs) in particulate matter (PM10) in Kumasi, Ghana. Environ Sci Pollut R. 2015:1-10.

16. Schwartz J. Air pollution and children's health. Pediatrics. 2004;113(4 Suppl):1037-43.

17. Etzel RA, Balk SJ. Handbook of Pediatric Environmental Health.Michigan: American Academy of Pediatrics; 1999.

18. Landrigan PJ, Carlson JE, Bearer CF, Cranmer JS, Bullard RD, Etzel RA, et al. Children's health and the environment: a new agenda for prevention research. Environ Health Perspect. 1998;106 Suppl 3:787-94.

19. Jacob J, Seidel A. Biomonitoring of polycyclic aromatic hydrocarbons in human urine. J Chromatogr B Analyt Technol Biomed Life Sci. 2002;778(1-2):31-47.

20. Viau C. Biological monitoring of exposure to mixtures. Toxicol Lett. 2002;134(1-3):9-16.

21. Jongeneelen FJ. Benchmark guideline for urinary 1-hydroxypyrene as biomarker of occupational exposure to polycyclic aromatic hydrocarbons. Ann Occup Hyg. 2001;45(1):3-13.

22. Wilhelm M, Hardt J, Schulz C, Angerer J, Human Biomonitoring Commission of the German Federal Environment A. New reference value and the background exposure for the PAH metabolites 1-hydroxypyrene and 1- and 2-naphthol in urine of the general population in Germany: basis for validation of human biomonitoring data in environmental medicine. Int J Hyg Environ Health. 2008;211(3-4):447-53.

23. Jongeneelen FJ, Anzion RB, Henderson PT. Determination of hydroxylated metabolites of polycyclic aromatic hydrocarbons in urine. JChromatogr. 1987;413:227-32.
24. Shahtaheri SJ, Ibrahimi L, Golbabaei F, Hosseini M, Fouladi Dehghi B. Solid phase extraction for 1-hydroxypyrene as a biomarker of occupational exposure to PAHs prior to high performance liquid chromatography. Iran J Chem Chem Eng. 2007;26(4).

25. Gatto MP, Gariazzo C, Gordiani A, L'Episcopo N, Gherardi M. Children and elders exposure assessment to particle-bound polycyclic aromatic hydrocarbons (PAHs) in the city of Rome, Italy. Environ Sci Pollut Res Int. 2014;21(23):13152-9.

26. Fiala Z, Vyskocil A, Krajak V, Viau C, Ettlerova E, Bukac J, et al. Environmental exposure of small children to polycyclic aromatic hydrocarbons. Int Arch Occup Environ Health. 2001;74(6):411-20.

27. Pongpiachan S, Tipmanee D, Khumsup C, Kittikoon I, Hirunyatrakul P. Assessing risks to adults and preschool children posed by PM2.5-bound polycyclic aromatic hydrocarbons (PAHs) during a biomass burning episode in Northern Thailand. Sci Total Environ. 2015;508:435-44

28. Northridge ME, Yankura J, Kinney PL, Santella RM, Shepard P, Riojas Y, et al. Diesel exhaust exposure among adolescents in Harlem: a community-driven study. Am J Public Health. 1999;89(7):998-1002.

29. Vyskocil A, Fiala Z, Chenier VV, Krajak L, Ettlerova E, Bukac J, et al Assessment of multipathway exposure of small children to PAH. Environ Toxicol Pharmacol. 2000;8(2):111-8.

30. Jongeneelen FJ. Biological monitoring of environmental exposure to polycyclic aromatic hydrocarbons; 1-hydroxypyrene in urine of people. Toxicol Lett. 1994;72(1-3):205-11.

31. Pornchai Sithisarankul Paolo Vineis Daehee Kang Nathaniel Rothman Neil C, Paul S. Association of 1 hydroxypyrene glucuronide in human urine with cigarette smoking and broiled or roasted meat consumption. Biomarkers. 1997;2(4):217-21.

32. Hansen AM, Raaschou-Nielsen O, Knudsen LE. Urinary 1-hy droxypyrene in children living in city and rural residences in Denmark. Sci Total Environ. 2006;363(1-3):70-7.

33. Mucha AP, Hryhorczuk D, Serdyuk A, Nakonechny J, Zvinchuk A Erdal S, et al. Urinary 1-hydroxypyrene as a biomarker of PAH exposure in 3-year-old Ukrainian children. Environ Health Perspect. 2006;114(4):603-9.

34. Hu Y, Zhou Z, Xue X, Li X, Fu J, Cohen B, et al. Sensitive biomarker of polycyclic aromatic hydrocarbons (PAHs): urinary 1-hydroxyprene glucuronide in relation to smoking and low ambient levels of exposure. Biomarkers. 2006;11(4):306-18.

35. Mielzynska D, Siwinska E, Kapka L, Szyfter K, Knudsen LE, Merlo DF. The influence of environmental exposure to complex mixtures including PAHs and lead on genotoxic effects in children living in Upper Silesia, Poland. Mutagenesis. 2006;21(5):295-304.

36. Aquilina NJ, Delgado-Saborit JM, Meddings C, Baker S, Harrison RM, Jacob P3, et al. Environmental and biological monitoring of exposures to PAHs and ETS in the general population. Environ Int. 2010;36(7):763-71.

37. Freire C, Abril A, Fernandez MF, Ramos R, Estarlich M, Manrique A, et al. Urinary 1-hydroxypyrene and PAH exposure in 4-year-old Spanish children. Sci Total Environ. 2009;407(5):1562-9. 